\title{
On defining moral enhancement: a clarificatory taxonomy
}

ABSTRACT

Recently there has been some discussion concerning a particular type of enhancement, namely 'moral enhancement'. However, there is no consensus on what precisely constitutes moral enhancement, and as a result the concept is used and defined in a wide variety of ways. In this article, we develop a clarificatory taxonomy of these definitions and we identify the criteria that are used to delineate the concept. We think that the current definitions can be distinguished from each other by the criteria used for determining whether an intervention is indeed moral enhancement. For example, some definitions are broad and include moral enhancement by any means, while other definitions focus only on moral enhancement by means of specific types of intervention (e.g. biomedical or genetic interventions).

Moreover, for some definitions it suffices for an intervention to be aimed or intended to morally enhance a person, while other definitions only refer to 'moral enhancement' in relation to interventions that are actually effective. For all these differences in definitions we discuss some of their (more normative) implications. This shows that definitions are significantly less descriptive and more normative than they are regularly portrayed to be. We therefore hope that the taxonomy developed in this paper and the comments on the implications for the normative debate of the variety of definitions will provide conceptual clarity in a complex and highly interesting debate.

\section{INTRODUCTION}

21 The debate about enhancing human traits has been raging for some decades, and more recently there has been some discussion concerning one particular category of enhancement, namely 'moral enhancement'. What is at issue in moral enhancement is not the improvement of physical and/or cognitive capacities, but improvement in the way in which we act or reflect morally. Concerns have been voiced that tinkering with our beliefs of what is right and wrong, or our motivation to act rightly or wrongly, might be to open a Pandora's box that could lead to unforeseen and potentially disastrous consequences [1-3]. Others praise moral enhancement as an essential step in guaranteeing even the 
very survival of the human race as the potential for doing great harm (e.g. with biological or other weapons of mass destruction) continues to increase [4-7].

Although the debate is of recent date, 'moral enhancement' or 'moral bioenhancement' has already become an established concept. Nevertheless, it is far from clear what precisely constitutes moral enhancement. Different authors use different definitions or meanings of term. Existing definitions can differ to such a degree that a particular intervention would constitute or result in moral enhancement according to one definition, but not according to another. However, even though many different definitions of the term exist, this is not always acknowledged in the debate. In this respect, John Shook has stated:

Too many discussions are proceeding as if both the meaning and the possibility of moral enhancement were already widely understood and agreed upon. (...) Asking such questions, and offering answers, depend on assigning some sense or another to "moral enhancement." However, clear and precise definitions of "moral enhancement" are not to be found; what has been called "moral" enhancement ranges from feeling empathic concern to increasing personal responsibility all the way to heightening respect for global fairness [8, p.3]

And also:

anyone using the term 'moral enhancement' as if everyone knows what is meant must either be simplifying matters to the point of negligence, or trying to speak only to those already in local moral consensus. [8, p.4]

We therefore believe that it is important to chart the different types of definition and so develop a taxonomy of existing definitions or uses of the concept of moral enhancement. We focus on a number of criteria for what counts as a moral enhancement that are included in some definitions but are not included or are included, but in a different form, in others. Whenever possible, we use definitions given by authors in their articles and stay as close as possible to the author's wording. However, not 
every author gives an explicit definition, and in some cases we must therefore focus on how these authors use the concept of moral enhancement and in what context.

Of course, creating a descriptive taxonomy can only be a first step in the debate on moral enhancement, as is clear from the quotes from Shook given above. Another issue that is rarely acknowledged in the debate on moral enhancement, is that behind the seeming neutrality of defining the concept, there often lie philosophical battles as to what constitutes morality and what it means to act morally. In this paper we will therefore also discuss the (normative) implications of using certain types of definition and of including or excluding certain elements from the definition. Our aim is to go beyond the simplification and local moral consensus described by Shook above, to chart the complexity of the concept and its implications for the normative debate on the permissibility or desirability of specific interventions aimed at moral enhancement.

We believe a descriptive taxonomy, combined with a discussion of some of the main implications of using certain types of definition, are important tools for anyone wishing to conduct a normative analysis of the ethical desirability of moral enhancement. We will distinguish different definitions of moral enhancement based on the criteria they use for determining whether a certain intervention is indeed a moral enhancement. We each time focus on a single criterion whereby we discuss (1) how definitions can be distinguished based on their inclusion or exclusion of this criterion, and (2) what the possible (normative) implications are of including or excluding it. For example, some definitions are broad and include moral enhancement by any means, while other definitions focus only on moral enhancement by means of specific types of intervention (e.g. biomedical or genetic interventions). Another element is that some definitions consider as moral enhancement those interventions that change a person's moral behaviour while for other definitions an intervention can only be seen as a moral enhancement when it targets a person's moral capacities. However, in this paper we will take no position on the definitions or criteria we prefer or disagree with, and we will not formulate definitions of our own. 


\section{FOCUS ON THE INTERVENTION OR ON THE INDIVIDUAL}

When comparing different definitions or uses of the concept of 'moral enhancement', one has to make sure one is not comparing apples and oranges. Many publications touch on the question: what is moral enhancement? However, this question seems to be understood in two different ways. Some authors formulate the question as: when can a certain intervention be considered a moral enhancement?. In doing so, they focus on the criteria that need to be met by the interventional process. David DeGrazia, for example, seems to understand moral enhancements as:

interventions that are intended to improve our moral capacities such as our capacities for sympathy and fairness'. [9, p.1]

Other commentators focus less on the intervention, and seem to understand the question of what is moral enhancement as: when can an individual be seen to have been morally enhanced or what does it mean for an individual to be morally enhanced? James Hughes, for example, argues for a conception of moral enhancement that focuses heavily on the individual rather than the intervention:

Moral enhancement is not just the jacking up of virtue with neurochemicals. It is more broadly taking conscious control of our lives to build the kind of character we want to have. [10, p.4]

It will be clear that focusing on the intervention rather than on the individual allows consideration of the efficacy of the intervention in particular cases to be deferred, and even that the nature of the moral improvement becomes less central.

\section{BROAD VERSUS MORE SPECIFIC INTERVENTIONAL MEANS}

Another difference is that some authors $[8 ; 11-13]$ use moral enhancement as a broad concept that covers any practice that causes or is intended to cause a change in the functioning of moral capacities, with types of interventions ranging from non-invasive (e.g. moral education) to highly invasive (e.g. deep brain stimulation or brain surgery). Others $[4,14]$ are more specific and focus on moral bioenhancement which they seem to understand as 'moral enhancement by biomedical and genetic means' [4, p.162]. Hence, these authors make explicit that they only focus on certain (invasive) means 
111 for enhancement, thereby leaving out such interventions as moral education or talk therapy. A

112 particular example of a specific focus can be found in an article by Mark Walker which discusses

113 'enhancing genetic virtue', a specific way of morally enhancing individuals:

114 Engineering genetic virtue (...) would mean promoting genes that influence the acquisition of the virtues. [15, p.26]

117 It is clear that certain (more invasive) interventions are more controversial than other (less invasive)

118 ones such as talk therapy and moral education. When one limits moral enhancement to more controversial cases, it is clear that when it comes to arguing for the ethical desirability of moral enhancement, a stronger justification will be needed.

Moreover, using a broad conception of moral enhancement seems to imply that interventions such as moral education and neurological interventions do not differ in principle (as they are both captured under the heading of 'moral enhancement'), but solely in terms of their practical implications/effects, for example, invasiveness or effectiveness. Using the concept of moral enhancement for all interventions or only for those interventions that are (most) invasive, can serve to bias the normative debate towards or away from a conclusion of permissibility or desirability.

\section{ENHANCING INDIVIDUALS VERSUS ENHANCING HUMANITY}

Definitions can differ in what they consider to be the target of moral enhancement. Most definitions stipulate that 'moral enhancement' refers to interventions that are used on individual persons. For example, Tom Douglas [16,17] defines moral enhancement as: interventions that will expectably leave an individual with more moral (viz. morally better) motives or behaviour than she would otherwise have had. [17, p.3]

Some commentators, however, use a definition that also seems to include interventions that operate on 137 groups of persons, or even on society and/or humanity in general. This is the case, for example, for Ingmar Persson and Julian Savulescu who discuss enhancing 'the moral character of humanity’ [4]. 
140 To illustrate the difference between morally enhancing individuals and morally enhancing society,

141 consider the following imaginary case: A country's government passes a law that requires that for every case of In Vitro Fertilisation, only embryos that do not possess a certain set of genes associated with a higher risk of developing anti-social personality disorder are suitable candidates for implantation.

In this case one could claim - following well-known arguments made by Derek Parfit in his Reasons and Persons [18] - that no individual would end up with better motives or behaviour than she would otherwise have had (as she either would not have been born or would have been chosen anyway), yet the society she lives in might end up with more people behaving morally. The theoretical possibility of such moral enhancement through genetic selection has been discussed by Walker [15] and Halley Faust [19]. According to definitions such as the one mentioned above by Douglas, such a program of pre-implantation genetic testing and selection would simply not be considered to be a moral enhancement as, following arguments voiced by Parfit, no individual could claim to be morally improved and so would fall outside the normative debate in this field. As with the previous section, excluding the 'difficult' and including the 'easy' both have implications for the debate. These definitions, covering the individual alone or covering society as well, thus also have relevant implications. For justifying moral enhancement applied solely to individuals, justifications related to autonomy and personal benefit might suffice. However, in justifying moral enhancement on a societal level one would need to turn to other justifications such as issues of justice or of achieving a common good. Moreover, concerns about altering human nature would then come into view as well

\section{MORAL TREATMENT VERSUS MORAL ENHANCEMENT}

164 Many definitions understand moral enhancement as any form of moral improvement, regardless of 165 whether it involves an improvement towards average functioning of moral capacities or one towards above average functioning. However, there are exceptions. Nicholas Agar, for example, has explicitly 
criticised the definition used by DeGrazia (quoted above) for not differentiating between moral enhancement as improvement (something Agar considers to be synonymous with moral therapy), and moral enhancement beyond human norms. ${ }^{1}$ For Agar, an example of moral therapy would be 'endowing the likes of John Wayne Gacy or Ted Bundy with a normal sensitivity to suffering' [21, p.73]. Moral enhancement, on the other hand, 'has the purpose of boosting responsiveness to ethical or moral reasons to levels beyond that considered normal for human beings' [21, p.73]. For Agar, moral enhancement refers exclusively to interventions that raise people to a higher level of functioning of moral capacities that is infrequently observed among humans or even to levels beyond those ever observed. Agar considers moral therapy and moral enhancement to be sufficiently different not to be lumped together under one term.

Likewise, Dorothee Horstkötter et al. argue that bringing people to average levels of moral reflection or behaviour is medical treatment and not enhancement. They claim that: if there is a health problem, medical treatment is the reasonable reaction, while enhancement, either moral or otherwise, does not arise [22, p.27]

In order to be able to distinguish moral treatment from moral enhancement in this way, one needs to determine what constitutes an average or normal level of functioning of moral capacities or behaviour. Every intervention that brings a person to this average level would then be treatment, while enhancement would consist of improving beyond this average level. To put this somewhat more analytically, those who maintain a difference between treating and enhancing, have to be able, at least theoretically, to distinguish:

1) An intervention $(X)$, used on a person or group with a below average functioning of moral capacities and/or behaviour $\left(\mathrm{M}^{\mathrm{BA}}\right)$ that is intended to raise or succeeds at raising this person's or group's functioning of moral capacities and/or behaviour to an average level $\left(\mathrm{M}^{\mathrm{A}}\right)$

\footnotetext{
${ }^{1}$ The debate on a possible distinction between 'treatment' and 'enhancement' is, of course, by no means exclusive to the moral enhancement debate. Many commentators have already discussed the relevance or irrelevance of such a distinction for the general debate on enhancement [20].
} 

capacities and/or behaviour $\left(\mathrm{M}^{\mathrm{A}}\right)$ that is intended to raise or succeeds at raising this person's or group's functioning of moral capacities and/or behaviour to an above average level ( $\left.\mathrm{M}^{\mathrm{AA}}\right)$

An intervention $\mathrm{X}$ could then be considered 'treatment', while interventions of type $\mathrm{Y}$ could then be capacities and/or behaviour $\left(\mathrm{M}^{\mathrm{BA}}\right)$ that is intended to raise or succeeds at raising this person's or group's functioning of moral capacities and/or behaviour to an above average level $\left(\mathrm{M}^{\mathrm{AA}}\right)$

Classifying interventions of type $\mathrm{Z}$ is more difficult as this intervention has both a treatment and an enhancement aspect to it.

Put in a schematic way this becomes:

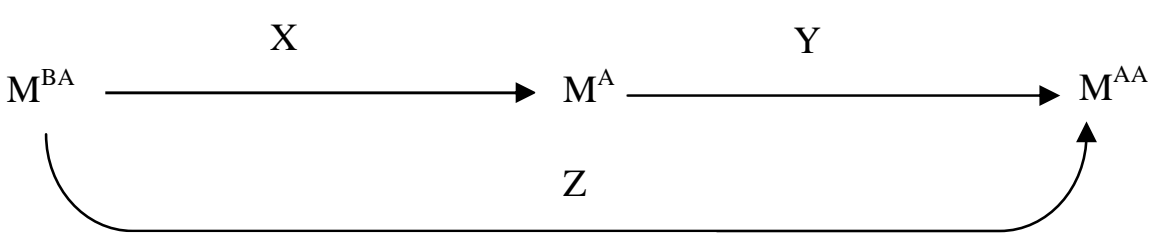

\section{Scheme 1: Three types of interventions}

However, spelling out the cut-off point between moral therapy and moral enhancement may often be next to impossible. $\mathrm{M}^{\mathrm{BA}}, \mathrm{M}^{\mathrm{A}}$, and $\mathrm{M}^{\mathrm{AA}}$ do not represent single and generally agreed upon levels of moral capacities. There is a continuum that ranges from below average functioning of moral capacities through to above average functioning. On this continuum, different cut-off points could be made as to

216 what falls within average functioning (and hence what falls outside), depending on how many standard

217 deviations from average one allows for an individual to still be considered as having normally

218 functioning moral capacities. As there is no objective way of determining what falls within the range 219 of 'normal' moral behaviour or functioning of moral capacities, every choice of cut-off point is, 
necessarily, a normative one. Even the question as to what constitutes 'moral capacities' has no

221 straightforward answer. ${ }^{2}$ Our proposed scheme only purports to create conceptual clarity, hence we

222 take no position as to where we believe the cut-off point should lie. We limit ourselves to pointing out

223 that different cut-off points can be made and that our scheme can be applied regardless of which cut-

224 off point one adopts.

226 Moreover, distinguishing moral treatment from moral enhancement raises other issues as it brings

227 morality within the medical domain. What seems to be implied by distinguishing moral enhancement

228 from moral treatment is not only that some people who lack in moral behaviour or capacities are

229 suffering from a disease or health problem, but also that they can sometimes be treated or cured. This

230 raises the question of whether, and if so under which conditions, certain forms of immorality should be

231 medicalized.

233 When one distinguishes moral treatment from moral enhancement, it also becomes impossible to

234 determine whether a particular intervention, in itself, is a moral enhancement or not. It is possible that

235 exactly the same intervention could be used in one case to raise a person to an average functioning of

236 moral capacities (intervention X), and in another case to raise a person to an above average

237 functioning of moral capacity (intervention Y). A single intervention could thus be a moral therapy or

238 a moral enhancement depending on the situation in which it is used.

239

240 Making a distinction between moral treatment and moral enhancement requires taking a normative

241 stance on what constitutes average or normal moral behaviour or average or normal moral capacities.

242 Even if one does not wish to make this distinction, however, claims about what constitutes an

\footnotetext{
${ }^{2}$ One might understand 'moral capacities' as being those capacities we actually use when making moral decisions (which capacities these are, is researched in moral psychology and neuroscience). [For example, a recent review on the neurobiology of morality argues that it is most plausible to depict moral processes as requiring the engagement of both emotional and cognitive neural networks) [29].] However, 'moral capacities' might also be used to refer to those capacities one believes one should use when making moral decisions, or capacities that, when used more or better, would lead to better moral decisions. These capacities might, for example, constitute the capacity for sympathy and fairness [9] or cognitive capacities [1].
} 
improvement of moral capacities or behaviour - which is just as much up for debate - are inevitable. If

244 one leaves out standards on what it means to improve moral behaviour or capacities, the concept

245 becomes indistinguishable from mere mental modification, as has been noted by Filippo Santoni de

246 Sio et al. [28].

248 Again, as noted in earlier sections, limiting or extending the definition of moral enhancement by

249 excluding the controversial or by including the uncontroversial clearly has implications for the 250 normative debate.

\section{INTENDED VERSUS EFFECTIVE INTERVENTIONS}

Another element of difference between existing definitions concerns the question whether moral enhancement only refers to interventions that are successful at improving a subject's moral capacity, or whether it also includes interventions that are merely intended or expected to improve moral capacity (regardless of whether they actually do).

The abovementioned definitions by DeGrazia [9] and Douglas [17] include cases of intended or expected but failed interventions. For them, what is important in determining whether an intervention is to be considered a moral enhancement is the intention with which the intervention is used.

John Harris, however, has reacted to this and has stated: them but rather in terms of their effect. [23, p.1]

Another example is Shook [8], for whom an intervention can be considered a moral enhancement if it affects an individual's moral beliefs, moral motives and/or moral behaviour. Thus, moral enhancement should do one or more of five things: 
2) Enhance a person's thoughtfulness about doing the right thing - resulting in stronger moral

272

273

274

275

279

280

281

282

283 decisions

3) Enhance a person's moral judgments that get the right moral answer - resulting in more correct moral judgments

4) Enhance a person's motivated choice to do what moral judgment indicates - resulting in improved moral intentions

5) Enhance a person's volitional power to act upon a moral intention - resulting in more will power [8, p.6; our italics]

Hence, for Harris and Shook an intervention that is intended to morally enhance a person, but fails to affect that person's moral reflection process or behaviour, is not a moral enhancement. This difference between moral enhancement as an intervention intended to enhance versus an intervention successful in achieving enhancement becomes relevant when it comes to moral justification. If, as Shook's definition seems to imply, an intervention can only be labelled a moral enhancement if it has a positive effect then one important reason to oppose moral enhancement is eliminated. Indeed, all problematic cases where no enhancement is reached or a person is left less moral than before the intervention, would quite simply not be considered cases of moral enhancement at all. This way of justifying moral enhancement would avoid all debate concerning potential risks, side-effects, etc.

\section{CAPACITIES-ORIENTED VERSUS BEHAVIOUR-ORIENTED INTERVENTIONS}

Some commentators in the moral enhancement debate label a certain intervention a moral enhancement depending on its (real or intended) effect on a person's behaviour. Others see moral enhancements as interventions that target or are intended to target a person's capacities of moral reflection. We shall refer to this difference as the difference between a behaviour-oriented and a capacities-oriented intervention.

Keeping in mind that an intervention of moral enhancement can target a person's behaviour or their capacities of moral reflection, any intervention can have one of four results. It can result in a person: 


\begin{tabular}{|l|lc|}
\hline Reflecting the same & Reflecting the same & 299 \\
Acting the same & Acting differently & 300 \\
& & 301 \\
\hline Reflecting differently & Reflecting differently & 302 \\
Acting the same & Acting differently & 303 \\
& & 304 \\
\hline
\end{tabular}

305

306

307

308

309

310

311

\section{Scheme 2: four possible results}

Currently existing definitions differ as to the question in which of the quadrants in the scheme given above one can find cases of moral enhancement. To clarify this difference, imagine the following extreme case:

Jack is a man with paedophilic urges who is currently incarcerated for having sexually molested a child. Despite a large amount of therapy, Jack fails to see what is wrong with him interacting with children in a sexual way. It is therefore decided to sedate Jack against his will and bring him to a surgery room. Neurosurgeons implant a chip (call this intervention $\mathrm{X}$ ) that will stop Jack from molesting children.

For this case, we need not deal with the question whether this intervention is ethically justified; we will merely focus on the question whether we should consider this to be 'moral enhancement'. This is a case similar to one suggested by DeGrazia [9] who considers this an extreme form of "moral bioenhancement'. In identifying which interventions can be labelled moral enhancements, some commentators rely heavily or solely on the intervention's achieved (or intended) effect on a person's behaviour [e.g. 17]. For them, intervention X, from the imaginary case above, changes Jack's behaviour for the better and hence would be considered moral enhancement, regardless of whether the intervention also affects Jack's moral capacities. Therefore, for those commentators defining moral enhancement in a behaviour-oriented way, interventions of moral enhancement can be found only in the right half of scheme 2 above (reflecting the same and acting differently \& reflecting differently and acting differently). 
328 It is also clear that the requirement for successful behaviour change would not suffice to label an

329 intervention a moral enhancement by certain other authors, but instead would be categorised by them

330 as a form of behaviour control (e.g. Harris) or moral therapy (e.g. Agar). Such an intervention could

331 either fall on the side of mere behaviour control, or on the side of moral therapy, depending on the

332 individual undergoing the intervention (e.g. an individual with or without a sexual disorder) and the

333 goal in question (e.g. as a means of rehabilitation or mere crime reduction by the criminal justice

334 system). Such differences in definition have implications for the acceptability of certain moral

335 enhancement interventions, and may render certain interventions more acceptable if labelled as a

336 moral enhancement rather than as a form of behaviour control. The latter, if misused, may result in

337 ethically dubious practices (cf. the chemical castration laws of certain US States) (see Focquaert [30]).

338 Hence, depending on one's definition, the term moral enhancement could be knowingly or

339 unknowingly misused to justify practices that would otherwise be deemed immoral.

341 Indeed, others understand moral enhancement in a different way, and argue that it does matter whether

342 or not an intervention affects the functioning of the subject's moral capacities. True, they might say, in

343 the imaginary case Jack will no longer molest children, but if the implant is put in place against Jack's

344 will and his subsequent actions do not stem from a moral judgment on Jack's behalf concerning what

345 is morally right and wrong, this is not a moral enhancement. ${ }^{3}$ In their view, making someone "more

346 moral' involves more than merely altering a person's behaviour. Or, as Harris puts it:

\footnotetext{
${ }^{3}$ Of course, again, we should not mistake the debate on what to call these interventions with debate on the ethical validity of such interventions. Authors such as Harris can consistently claim: (1) that an intervention such as the one performed on Jack is not a moral enhancement, and (2) that there might be some cases where such an intervention is morally justified.
} 
351 Fabrice Jotterand has also criticised the one-sidedness of focussing on behaviour. He argues that most

352 moral neuroenhancement is unlikely to morally enhance people in the true sense of the term and notes 353 that:

While the manipulation of moral emotions might change the behavior of an individual, it does not provide any content, for example, norms or values to guide one's behavioral response. [24, p.6]

In a similar vein, William Simkulet argues that:

(i) forcing agents to act rightly, (ii) preventing agents from acting wrongly, and (iii) making it harder for moral agents to act wrongly fail to constitute genuine moral enhancement. [25, p.17]

For these commentators, as well as for those who use similar lines of argumentation [e.g. 13, 26], the criterion for whether an intervention constitutes a moral enhancement is not behaviour, but whether the intervention affects or improves an individual's capacities for moral reflection. They situate moral enhancements in the lower half of scheme 2 (reflecting differently and acting the same \& reflecting differently and acting differently).

Defining moral enhancement in a capacities-oriented way has some important consequences. If moral enhancement indeed merely refers to interventions that improve a subject's capacities for moral

371 reflection, then it is possible to morally enhance an individual without this resulting into improved 372 moral behaviour. Moreover, it is not unlikely that, for example, when one improves an individual's moral beliefs, this does not result in improved moral behaviour, as it is well known that knowing the good does not automatically lead to doing the right thing. This also means that if one uses a capacities-oriented definition of moral enhancement, actually measuring whether and to what degree an individual is morally enhanced is difficult, since it would require an assessment of a person's

377 reflection processes. 
As such, the debate on whether moral enhancement can be better understood in a capacities-oriented or a behaviour-oriented way is often only the surface of more fundamental debates, for example on

381 how important freedom is for moral action. Can behaviour be called moral if it is not free? Indeed, only accepting changes in behaviour as a criterion for determining what constitutes moral enhancement leads one to claiming that certain interventions that cause an individual to display moral 384 behaviour in an automatic manner, are examples of moral enhancements. A relevant thought 385 experiment in this respect is that of the 'God Machine', formulated by Savulescu and Persson [30], a machine that monitors everyone's desires and intentions, and which intervenes every time a person forms an intention to perform a great moral evil (e.g. murder or rape) by simply changing that person's intention and thus her behaviour. In this scenario, people are still able to choose to do the right thing (i.e. not to murder or rape), but unable to chose or perform moral evil. Those authors defending a capacities-oriented approach might object that a person who initially intends to murder or rape but has

391 his mind changed by the God Machine is not at all morally enhanced, as his subsequent decision to act 392 or not act on that intention would not be free or autonomous. ${ }^{4}$ For authors such as Harris, an 393 intervention can only be a moral enhancement if it leaves the freedom to fall, i.e. to do the wrong 394 thing. Of course, focussing solely on the (intended or achieved) effect of interventions on a person's capacities for moral reflection, may commit one to calling certain interventions moral enhancements even though they may in no way change a person's behaviour.

398 One way to address this would be to combine the capacities-oriented and the behaviour-oriented 399 approaches. For example, one might say that an intervention is a moral enhancement if it changes 400 behaviour or if it changes one's capacities for moral reflection. This broadens the field of what is 401 moral enhancement (as it would only exclude interventions in the upper left corner of scheme 2 - i.e. reflecting the same and acting the same), but, of course, it also combines the problems mentioned 403 earlier.

\footnotetext{
${ }^{4}$ In this respect, Savulescu and Persson do mention at the end of their paper that '[s]uch interventions and such control are not plausibly moral enhancements of that person' [30, p.417]. They mainly argue for the God Machine on the grounds that there would be many positive effects and as such their view perhaps does not differ that much from authors such as Harris.
} 
Another possible response would be to say that an intervention is only a moral enhancement if it changes behaviour and it changes one's capacities for moral reflection. This allows one to avoid the problems mentioned earlier, but of course it also narrows the scope of moral enhancement. For, according to this way of delineating the concept, interventions of moral enhancement can only be found in the lower right corner of scheme 2 (i.e reflecting differently and acting differently). In some of his statements, Harris seems to be defending this position, for example when he says: It seems to me that moral enhancement, properly so called, must not only make the doing of good or right actions more probable and the doing of bad ones less likely, but must also include the understanding of what constitutes right and wrong action. [23, p.172; our italics]

\section{ACTIVE INVOLVEMENT VERSUS PASSIVE RECEIVING}

416 At the heart of the capacities-oriented versus behaviour-oriented debate mentioned above lies the

417 question of what is or should be targeted with moral enhancements - moral capacities, moral

418 behaviour, either one of them, or both. This is not the same as another distinction that is made in the moral enhancement debate, namely that between enhancement by means of a process requiring active involvement on behalf of the individual it is used on, and enhancement in which the subject of the intervention is a passive recipient. This distinction does not concern the target of a moral enhancement, but rather the way in which the enhancement is achieved. A moral enhancement by way

423 of active involvement would then be an enhancement requiring conscious mental processes in the 424 subject as a means to achieve its result. Moral education would be a classical example. In contrast, moral enhancement involving passive receiving would either be enhancement in an immediate way where no active involvement was possible (e.g. a pill with immediate effect) or enhancement by way of a process that required no deliberate involvement of the recipient (e.g. classical conditioning).

429 This distinction is relevant since, for some authors, the goal of moral enhancement is for individuals to 430 become more virtuous, and often these authors follow Aristotle in claiming that becoming virtuous is 431 always a conscious and deliberate process, where the way to becoming virtuous is just as essential as 
432 the result (being virtuous). Chris Zarpantine talks about 'the thorny and arduous path of moral

433 progress' [27, p.141], while Jotterand states:

434 Virtue is a behavioral habit under the supervision of reason that can be taught and learned. The control and manipulation of moral emotions by technological means reduce the human mind to neurochemical processes and threaten the very essence of moral agency, that is, autonomy. $[24, \mathrm{p} .7]$

This way of thinking about moral enhancement may lead some commentators to reject passive ways of enhancement as examples of genuine moral enhancement.

Interestingly, the distinction between moral enhancement by means of an active process and passive moral enhancement can sometimes be used to complement the capacities-oriented versus behaviouroriented debate. Among the interventions that target the functioning of a person's moral capacities, one could distinguish those interventions that do so using an active process (e.g. moral education) from those that do so in a passive way (e.g. a pill to clear up one's moral reflection). However, interventions that solely target a person's behaviour, will generally do so in a passive way (e.g. implants to make a person exhibit a certain behaviour), as moral enhancement by means of active involvement requires conscious mental processes and, unless the subject is simply trying to learn how to pass himself off as a moral person, will thus always also affect the person's capacities for moral reflection.

453 Whether one thinks of moral enhancement as a process requiring active involvement or as (also) covering more passive ways of changing capacities and/or behaviour, has important implications. It matters with regard to the relation between the person (or group) doing the enhancing and the person

456 (or group) being enhanced and the voluntariness of the enhancement. In moral interventions requiring 457 active involvement, the person being enhanced is at least aware of the process, is given an important 458 role and, most likely, is free to stop the process as her cooperation is essential. For more passive 459 interventions, it is possible to enhance a person against their will or even without them knowing they 
are being morally enhanced, which is clearly morally problematic. For these reasons, interventions of moral enhancement that do not require active involvement of the person being enhanced will most

462 likely be more controversial.

463

\section{CONCLUDING REMARKS}

465 In this paper we have tried to show that the term 'moral enhancement' is used in ways that cover a 466 large variety of different practices. First we examined and made explicit the different ways in which 467 the concept is used and defined, and we identified the criteria that are used to delineate the concept. 468 Next we showed that, despite claims of being descriptive, it is often well nigh impossible to separate a definition's descriptive content from its normative content. While some differences, have relatively limited implications, perhaps simply in skewing the normative debate, other differences have more

471 far-reaching implications and are revealing of underlying normative theories or positions.

473 Particular implications that result from the choices made when faced with the alternative definitions

474 identified in the preceding sections can be summarised as follows:

475 (1) Broad versus specific means of moral enhancement carry implications with regard to the invasiveness and practical effects of the intervention in question. More invasive interventions clearly need a stronger justification. Moreover, definitions including broad means of moral enhancement may

478 obscure the often-voiced concern that biomedical means of enhancement pose a greater threat to 479 concepts of authenticity and identity compared to non-biomedical means.

480 (2) Conceptualizing moral enhancement on an individual level versus a level which includes society 481 has implications for its justification. For example, potential instances of invasive societal moral 482 enhancement will need greater justification compared to individual level and non-invasive societal enhancements. Both specific safeguards pertaining to the rights and needs of the individual and a 484 justification pertaining to the rights and needs of society are likely to be required in the first case.

485 Certain less invasive interventions, such as moral education, may on the other hand be decided 486 through a democratic mandate and may not necessarily require consent from each individual in 487 question. 
488 (3) Whether one includes or excludes moral treatment from the scope of moral enhancement has

489 implications regarding the medicalization of immoral behaviour and the desirability or undesirability

490 of labelling (some forms of) immoral behaviour as a disease. Distinguishing moral treatment from

491 moral enhancement has another implication. Anyone who accepts a distinction between moral

492 treatment and moral enhancement has to, at least in theory, acknowledge a level of 'average'

493 functioning or behaviour in order to distinguish treatment from enhancement. This brings with it

494 significant difficulties as determining what is average functioning or behaviour inherently involves a

495 normative decision.

496 (4) Restricting moral enhancement to covering only effective interventions has implications for its

497 moral justification. Classifying potentially non-effective interventions as moral enhancement needs

498 additional justification compared to effective interventions since the beneficial effect can be regarded

499 as an important justificatory reason for pursuing specific enhancement interventions.

500 (5) Focusing on capacities versus behaviour as the target of moral enhancement may have important

501 implications for one's implicit or intuitive acceptance of the interventions in question. Certain

502 interventions that can be considered immoral under specific circumstances (e.g. physical or chemical

503 castration by the criminal justice system in the Czech Republic), may appear more acceptable if

504 framed under the label of 'moral enhancement'. This could lead to certain ethically dubious practices

505 being more widely accepted and more easily institutionalized. Moreover, the capacities/behaviour

506 distinction also has important implications for the value of freedom in morality and whether or not

507 morality requires 'the freedom to fall'.

508 (6) Passive enhancement interventions have the potential to circumvent an individual's approval and

509 may therefore more easily be considered controversial, especially if one considers society-wide

510 passive enhancement (e.g. the addition of some kind of neurochemical to drinking water). Greater

511 caution may thus be required when implementing passive interventions. Moreover, some normative

512 ethical positions may not regard passive interventions as moral enhancements at all, and may

513 therefore, justifiably or unjustifiably, exclude consideration of all passive means when moral

514 enhancement is considered. 
516 Moreover, the particular approach one takes to normative ethical questions may have important

517 implications. For some utilitarian thinkers, if an intervention achieves behavioral control, this may be

518 sufficient for it to be labeled a moral enhancement, whereas this is not likely to be the case for, for

519 example, a virtue ethicist. For a rights-based ethicist, the 'freedom to fall' will typically be considered

520 to be an essential part of morality. For a virtue ethicist, passive interventions do not amount to moral

521 enhancements, whereas, provided certain safeguards are met, such interventions may count as

522 enhancements for utilitarian ethicists and rights-based ethicists. These underlying normative views are

523 important and may have a huge impact on one's preferred definition of moral enhancement. The

524 capacities-oriented versus behavior-oriented approaches show, for example, how Harris would label

525 some interventions that Douglas considers 'moral enhancement' to be examples of mere behavior

526 control because in those examples the subjects lack the freedom to fall. Similarly, virtue ethicists may

527 not consider certain interventions proposed by Douglas and/or Persson and Savulescu to be moral

528 enhancements since some of these do not rely on the active involvement of the subject. If definitions a

529 priori rule out certain forms of moral enhancement or a priori include interventions that would not be

530 labeled moral enhancements by others, then this needs to be mentioned and explicitly acknowledged

531 in order for the debate to be able to move forward in a constructive and open manner.

532

533 This paper should not be read as a plea for one single and universally agreed upon definition. There

534 are many different types of interventions for which the concept can be used. We believe there need be

535 no problem with leaving 'moral enhancement' simpliciter as an umbrella term that may be used for

536 many kinds of interventions, as long as one makes it sufficiently clear just how one is using the

537 concept or what one is having it refer to and is aware of how one's underlying normative position may

538 influence one's understanding of the concept. Our paper is also not a plea for a descriptive definition

539 for, as we hope to have made clear throughout the paper, expelling all normative elements from such a

540 definition is impossible. What we wish to emphasise is that most authors fail to identify the impact of

541 their normative positions on their proposed definition of moral enhancement, and may thus, knowingly

542 or unknowingly, portray their definition as neutral. This may lead one to believe that a given definition

543 frames all the different aspects of the debate and all the different interpretations of what should and 
544 should not be labeled a moral enhancement. Explicitly acknowledging one's normative stance and 545 how this might impact one's views will likely ameliorate the current normative debate and provide for 546 a more constructive approach to the question of the ethical desirability of specific interventions."

547

548 We hope that this paper will enable progress in the debate on moral enhancement, by providing a

549 taxonomy of the many different definitions and uses of the term 'moral enhancement', which had been

550 lacking to date, and by discussing several implications of particular definitions for the normative

551 debate on moral enhancement.

552

\section{REFERENCES}

554 1. Harris, John. 2011. Moral Enhancement and Freedom. Bioethics 25(2): 102-111.

555

556 2. Harris, John. 2012. What It's Like to Be Good. Cambridge Quarterly of Healthcare Ethics 21(3):

$557 \quad 293-305$.

558

559 3. Wasserman, David. 2013. When bad people do good things: will moral enhancement make the

560 world a better place. Journal of Medical Ethics. doi:10.1136/medethics-2012-101094

561

562 4. Persson, Ingmar and Julian Savulescu. 2008. The Perils of Cognitive Enhancement and the Urgent

563 Imperative to Enhance the Moral Character of Humanity. Journal of Applied Philosophy 25(3): 162564177.

565

566 5. Persson, Ingmar and Julian Savulescu. 2011. The turn for ultimate harm: a reply to Fenton. Journal 567 of Medical Ethics 37: 441-444.

568

569 6. Persson, Ingmar and Julian Savulescu. 2012. Unfit for the Future: The Need for Moral

570 Enhancement. Oxford: Oxford University Press.

571 
572 7. Fenton, Elizabeth. 2010. The perils of failing to enhance: a response to Persson and Savulescu.

573 Journal of Medical Ethics 36: 148-151.

574

575 8. Shook, J.R. 2012. Neuroethics and the Possible Types of Moral Enhancement. AJOB Neuroscience, 576 3(4), pp.3-14.

577

578 9. DeGrazia, David. 2013 Moral enhancement, freedom, and what we (should) value in moral

579 behaviour. Journal of Medical Ethics. doi:10.1136/medethics-2012-101157

580

581 10. Hughes, James. 2011. After Happiness, Cyborg Virtue. Free Inquiry 32(1): 1-7.

582

583 11. Harris, John. 2013. "Ethics is for bad guys!" Putting the "moral” into moral enhancement.

584 Bioethics 27(3): 169-173.

585

586 12. Harris, John. 2013. Moral Progress and Moral Enhancement. Bioethics 27(5): 285-290.

587

588 13. Lev, Ori. 2012. Enhancing the Capacity for Moral Agency. AJOB Neuroscience 3(4): 20-22.

589

590 14. Agar, Nicholas. 2013. A question about defining moral bioenhancement. Journal of Medical

591 Ethics. doi:10.1136/medethics-2012-101153

592

593 15. Walker, Mark. 2009. Enhancing genetic virtue. Politics and the Life Sciences 28(2): 27-47.

594

595 16. Douglas, Thomas. 2008. Moral Enhancement. Journal of Applied Philosophy 25(3): 228-245.

596

597 17. Douglas, Thomas. 2011. Moral Enhancement Via Direct Emotion Modulation: A Reply to John

598 Harris. Bioethics 27(3): 160-168.

599 
18. Parfit, Derek. 1989. Reasons and Persons. Oxford: Clarendon Press.

601

602

19. Faust, Halley S. 2008. Should we select for genetic moral enhancement? A thought experiment

603

using the MoralKinder (MK+) haplotype. Theoretical Medicine and Bioethics 29: 397-416.

604

605

20. Daniels, Norman. 2000. Normal Functioning and the Treatment-Enhancement Distinction.

606 Cambridge Quarterly of Healthcare Ethics 9: 309-322.

607

608

21. Agar, Nicholas. 2010. Enhancing genetic virtue? Politics and the Life Sciences 29(1): 73-75.

609

610

22. Horstkötter, Dorothee, Ron Berghmans, and Guido de Wert. 2010. Moral Enhancement for

611

Antisocial Behavior? An Uneasy Relationship. AJOB Neuroscience 3(4): 26-28.

612

613

23. Harris, John. 2013. Taking liberties with free fall. Journal of Medical Ethics.

614 doi:10.1136/medethics-2012-101092.

615

616

24. Jotterand, Fabrice. 2011 "Virtue Engineering" and Moral Agency: Will Post- Humans Still Need

617 the Virtues? AJOB Neuroscience 2(4): 3-9.

618

619

25. Simkulet, William. 2012. On Moral Enhancement. AJOB Neuroscience 3(4): 17-18.

620

621 26. Baertschi, Bernard. 2012. Neuromodulation in the Service of Moral Enhancement. Brain

622 Topography. doi:10.1007/s10548-012-0273-7.

623

624 27. Zarpentine, Chris. 2013. "The Thorny and Arduous Path of Moral Progress": Moral Psychology

625 and Moral Enhancement. Neuroethics 6: 141-153.

626 
627 28. Santoni de Sio, Filippo, Hannah Maslen, and Nadira Faulmüller. 2012. The Necessity of Objective 628 Standards for Moral Enhancement. AJOB Neuroscience 3(4): 15-16.

629

630 29. Pascual, Leo, Paulo Rodrigues, David Gallardo-Pujol. 2013. How does morality work in the brain?

631 A functional and structural perspective of moral behavior. Frontiers in Integrative Neuroscience 7(65).

632 doi: 10.3389/fnint.2013.00065.

633

634 30. Savulescu, Julian, Ingmar Persson. 2012. Moral Enhancement, Freedom, and the God Machine.

635 The Monist 95(3): 399-421.

636 